DOI: $10.38136 / j g o n .885842$

\title{
Anne Sütündeki Leptin, Ghrelin, Adiponektin ve IGF-1 Hormonlarının Maternal BKi ve Bebeğin Büyümesi ile İlişkisi
}

\section{Relationship of Leptin, Ghrelin, Adiponectin and IGF-1 Hormones in Breast Milk with Maternal BMI and Infant Growth}

\author{
Tuğçe TEKIN GÜLER \\ (1) Orcid ID:0000-0002-9876-5487 \\ Nevra KOÇ 2,3 \\ (1) Orcid ID:0000-0002-4358-4443 \\ Aysun KARA UZUN 4,5 \\ (1) Orcid ID:0000-0002-1028-5949 \\ Mehmet FISUNOĞLU ${ }^{1}$ \\ (1) Orcid ID:0000-0002-0021-7811
}

\author{
${ }^{1}$ Hacettepe Üniversitesi, Sağlık Bilimleri Fakültesi, Beslenme ve Diyetetik Bölümü, Ankara, Türkiye \\ ${ }^{2}$ Ankara Șehir Hastanesi, Beslenme ve Diyetetik Bölümü, Ankara, Türkiye \\ ${ }^{3}$ Ankara Çocuk Sağlığı Hastalıkları Hematoloji Onkoloji Eğitim ve Araștırma Hastanesi, Beslenme ve Diyetetik Bölümü, \\ Ankara, Türkiye \\ ${ }^{4}$ Ankara Șehir Hastanesi, Sosyal Pediatri Bölümü, Ankara, Türkiye \\ ${ }^{5}$ Ankara Çocuk Sağlığı Hastalıkları Hematoloji Onkoloji Eğitim ve Araștırma Hastanesi, Sosyal Pediatri Bölümü, Ankara, \\ Türkiye
}

\section{öz}

Amaç: Maternal beden kütle indeksinin anne sütündeki leptin, ghrelin, adiponektin ve IGF-1 düzeylerine etkisini belirlemek ve anne sütündeki bu hormonların bebeğin büyümesi ile ilişkisini değerlendirmektir.

Gereç ve Yöntemler: Bu araştırmaya Mayıs 2018-Temmuz 2018 tarihleri arasında Ankara Çocuk Sağığı ve Hastalıkları Hematoloji Onkoloji Eğitim ve Araştırma Hastanesine başvuran, 2 aylık bebeği olan ve bebeğine sadece anne sütü veren, 20 normal vücut ağırlığına sahip ve 20 obez anne dahil edildi. Bebeklerin doğumdaki ve 2 aylık kontrollerindeki vücut ağırıkları ve boyları kaydedildi. Anne sütündeki hormon konsantrasyonları uygun Elisa kitleri kullanılarak ölçüldü.

Bulgular: Anne sütündeki leptin, ghrelin, adiponektin ve IGF-1 konsantrasyonlarında normal vücut ağırlı̆ı̆na sahip anneler ile obez anneler arasında anlamlı bir fark bulunmamıştır $(p>0,05)$. Anne sütündeki leptin hormonu ile gebelik öncesi maternal beden kütle indeksi ve postpartum 2. ay maternal beden kütle indeksi arasında pozitif bir korelasyon gösterilmiştir (sırasıyla $r=0,829 ; p=0,021, r=0,857 ; p=0,014$ ). Çalışmaya katılan tüm bebeklerin ağırlık kazanımı ile anne sütündeki ghrelin hormonu arasında pozitif bir ilişki varken $(r=0,406 ; p=0,011)$, adiponektin hormonu ile negatif bir ilişki bulunmuştur $(r=-0,336 ; p=0,034)$. Bebeklerin 2 . aydaki boya göre $z$ skoru değerleri ile normal vücut ağırlı̆ı̆na sahip annelerin anne sütündeki leptin ile negatif $(r=-0,857 ; p=0,014)$, obez annelerin anne sütündeki ghrelin ile pozitif ilişki tespit edilmiştir $(r=0,446 ; p=0,049)$.

Sonuç: Maternal beden kütle indeksi anne sütündeki hormon düzeylerini etkileyebilir ve anne sütündeki leptin, adiponektin ve ghrelin düzeyleri bebeğin erken dönemdeki büyümesini etkileyebilmektedir.

Anahtar kelimeler: Anne sütü; bebek büyümesi; iştah hormonlarl; maternal beden kütle indeksi.

\section{ABSTRACT}

Aim: The aim of this study is to determine the effect of maternal body mass index on leptin, ghrelin, adiponectin and IGF-1 levels in breast milk and to evaluate the relationship of these hormones with infant growth.

Material and Methods: The study was conducted on 20 normal-weight and 20 obese mothers, who had a 2-month-old exclusively breastfed infants, who admitted to Child Health and Diseases, Hematology, Oncology Training and Research Hospital in Ankara from May 2018 to July 2018. Body weights and heights of infants at birth and at the 2-month-follow-up were recorded. Hormone concentrations in breast milk were measured by Elisa kits.

Results: There was no significant difference leptin, ghrelin, adiponectin and IGF-1 concentrations in breast milk between normal-weight and obese mothers $(p>0.05)$. Leptin hormone in breast milk was positively correlated with pre-pregnancy maternal body mass index and postpartum $2 n d$ month maternal body mass index $(r=0.829$; $p=0.021, r=0.857 ; p=0.014$, respectively). While there was a positive correlation between infants' weight gain and ghrelin hormone in breast milk $(r=0.406 ; p=0.011)$, there was a negative correlation between infants' weight gain and adiponectin hormone $(r=-0.336 ; p=0.034)$. Infant weight for length $z$ score at 2 months was negatively correlated with leptin in the breast milk of normal-weight mothers ( $r=-0.857$; $p=0.014)$, but not ghrelin in the breast milk of obese mothers $(r=0.446 ; p=0.049)$.

Conclusion: Maternal body mass index may affect the hormone levels in breast milk and leptin, adiponectin and ghrelin levels in breast milk may affect the growth of infants during early postnatal life.

Keywords: Breast milk; infant growth; appetite hormones; maternal body mass index.

Sorumlu Yazar/ Corresponding Author:

Mehmet Fisunoğlu

Adres: Hacettepe Üniversitesi, Sağlık Bilimleri Fakültesi, Beslenme ve Diyetetik Bölümü, Ankara, Türkiye 06100

E-mail: fisunogl@hacettepe.edu.tr 


\section{GíRiş}

Anne sütü; bebeğin ihtiyacı olan besin gereksinimini, uygun büyümeyi, immün korumayı ve fizyolojik gelişimi destekleyen, benzersiz bir bileşime sahip olan, makro ve mikro besin ögeleri, hormonlar, antikorlar, biyoaktif moleküller içeren optimal bir besindir (1). Dünya Sağlık Örgütü (DSÖ) tarafından doğumdan sonraki 6 ay süresince bebeklerin sadece anne sütü ile beslenmesi ve 2 yaşa kadar da tamamlayıcı besinler ile birlikte anne sütünün beslenmenin bir parçası olarak sürdürülmesi önerilir (2). Anne sütü enerji ve besin öğesi içeriğinin yanı sıra biyoaktif faktörlere de sahip olduğundan bebeğin gelişiminin sağlanması ve sürdürülmesi için en uygun besindir (3). Öte yandan anne sütü bileşimi; annenin yaşına, laktasyon süresine, emzirme süresine, emzirme zamanına, gestasyonel yaşa, pariteye, maternal beslenmeye, maternal beden kütle indeksine (BKi), kişisel farklııklara ve diğer pek çok faktöre bağlı olarak değişkenlik gösterebildiği için son derece de komplekstir. (4-6).

Anne sütünde de yer aldığı gösterilmiş olan, leptin, adiponektin ve ghrelin iştahın düzenlenmesinde rol oynayan önemli hormonlardandır (7-10). Besin alımının ve vücut kompozisyonunun düzenlenmesinde merkezi bir rol oynayan bu hormonlar büyüme üzerinde etkili olabilir (11). Ayrıca yapısal ve metabolik olarak insüline benzeyen anabolik bir hormon olan insülin benzeri büyüme faktörü-1'in (IGF-1) anne sütünde de bulunduğu tespit edilmiştir. Anne sütündeki IGF-1 seviyeleri ile bebeğin ağırlık kazanımı pozitif ilişkilendirilmiştir (12). Bu çalışmanın amacı, maternal BKI'nin anne sütündeki leptin, ghrelin, adiponektin ve IGF-1 düzeylerine etkisini belirlemek ve anne sütündeki bu hormonların bebeğin büyümesi ile ilişkisini değerlendirmektir.

\section{GEREÇ VE YÖNTEMLER}

Araştırmaya Ankara Çocuk Sağlığı ve Hastalıkları Hematoloji Onkoloji Eğitim ve Araştırma Hastanesinin Sağlam Çocuk Polikliniğine başvuran, 2 aylık bebeği olan ve bebeğine sadece anne sütü veren, araştırmaya katılmaya gönüllü 20 normal vücut ağılığına sahip ve 20 obez anne dahil edilmiştir. Annelerin normal vücut ağırığı veya obez olma durumları gebelik başlangıcındaki vücut ağırlıklarına göre değerlendirilmiştir. Gebelikten önceki BKI 18,5-24,9kg/m2 olanlar normal vücut ağırlığında, $B K I \geq 30,0 \mathrm{~kg} / \mathrm{m} 2$ olanlar obez olarak sınıflandırılmışıı (13). Araştırmaya 37-42 hafta arasında normal yolla doğum yapan sağlıklı anneler ve 2500 g'ın üzerinde doğum ağırlığına sahip olan sağlıkı bebekleri dahil edilmiştir. Çoklu gebeliği olanlar, 2500 g'ın altında doğum yapanlar, bebekte majör komplikasyon olanlar, gebelik sırasında preeklampsi veya gestasyonel diyabet gibi kronik hastalığı olanlar, emzirmeyi kısıtlayan komplikasyonu olanlar ile sigara, alkol veya herhangi bir bağımlığı olan anneler araştırmaya dahil edilmemiştir. Araşırımanın etik uygunluğu Hacettepe Üniversitesi Girişimsel Olmayan Klinik Araştırmalar Etik Kurulu tarafından değerlendirimiş ve GO 17/843-13 sayılı karar ile uygun görülmüştür. Araştırma kesitsel bir vaka kontrol çalışması olarak planlanmıştır. Sağlam Çocuk Polikliniğine gelen anneler araştırma hakkında bilgilendirilmiştir. Araştırmaya dahil olmayı kabul eden gönüllülere onam formu imzalatıldıktan sonra yüz yüze araştırma anketi uygulanmıştır. Anket genel özellikler, besin desteği kullanımı ve beslenme alışkanlıkları, bebek ve emzirme ile ilgili bilgiler, antropometrik ölçümler, fiziksel aktivite durumları ve alışkanlıkları bölümlerinden oluşmaktadır. Annelerin gebelik öncesi vücut ağırıkları anket ile sorgulanırken, postpartum 2. aydaki vücut ağırıkları anket sırasında ölçülmüştür. Bebeklerin doğum ağırlıkları ve boyları hasta dosyasından, 2 aylık değerleri ise muayene sırasında ölçülmüştür. Vücut ağırlığı ölçümü bebek terazisi kullanılarak, boy uzunluğu ölçümü infantometre kullanılarak yapılmıştır. Bebeklerin boya göre ağırlık z skor değerleri DSÖ'nün çocuk büyümesi standartlarına göre hesaplanmıştır (14).

Annelerden, anne sütünde bulunan leptin, ghrelin, adiponektin ve IGF-1 düzeylerinin tespit edilmesi için son 1 saat içinde bebeğini emzirmedikleri memeden elektrikli ve pilli göğüs pompası kullanılarak yaklaşık $5 \mathrm{~mL}$ anne sütü örneği alınmıştır. Toplanan anne sütleri santrifüjlenmiş ve yağ tabakası çıkarıldıktan sonra $-80^{\circ} \mathrm{C}$ 'de saklanmıştır. Hormon konsantrasyonları uygun Elisa kitleri kullanılarak ölçülmüştür.

İstatistiksel analiz

Verilerin istatiksel değerlendirilmesinde Statistical Package for the Social Sciences (SPSS) 22 programı kullanılmıştır. Tamamlayıcı veriler ortalama $(\mathrm{x}])$, standart sapma (SS), ortanca, alt ve üst değerler olarak sunulmuştur. İki bağımsız grubun verilerinin ortalamalarının karşılaştııımasında Mann Whitney $U$ testi kullanılmıştır. Veriler arasındaki korelasyon analizlerinde Spearman korelasyon testi ile yapılmıştır. Sonuçlar \%95 güven aralığında $p$ değeri 0,05 altında olduğunda anlamlı sayılmıştır.

\section{BULGULAR}

Çalışmaya BKI'si normal aralıkta olan 20 anne ile BKI'ye göre obez olan 20 anne ve bebekleri dahil edilmiştir. Annelerin ve bebeklerin özellikleri Tablo 1'de verilmiştir. 
Tablo 1: Annelerin ve bebeklerin özellikleri

\begin{tabular}{|c|c|c|c|}
\hline & Normal & Obez & \\
\hline & $\begin{array}{c}\bar{x} \pm S S \\
\text { (Alt-Üst) }\end{array}$ & $\begin{array}{c}\bar{x} \pm S S \\
\text { (Alt-Üst) }\end{array}$ & $\mathbf{p}$ \\
\hline \multicolumn{4}{|l|}{ Anneler } \\
\hline Yaş (yıl) & $\begin{array}{c}27,1 \pm 4,5(19,0- \\
34,0) \\
\end{array}$ & $\begin{array}{c}29,5 \pm 5,3 \\
(20,0-35,0) \\
\end{array}$ & 0,125 \\
\hline Parite & $\begin{array}{c}1,7 \pm 0,8(1,0- \\
3,0)\end{array}$ & $\begin{array}{c}2,4 \pm 0,7(1,0- \\
3,0)\end{array}$ & $0,009 *$ \\
\hline $\begin{array}{l}\text { Gebelik öncesi BKi } \\
\left(\mathrm{kg} / \mathrm{m}^{2}\right)\end{array}$ & $\begin{array}{c}22,7 \pm 2,0(18,7- \\
24,9) \\
\end{array}$ & $\begin{array}{c}31,8 \pm 2,7 \\
(30,1-40,2)\end{array}$ & $0,000 *$ \\
\hline $\begin{array}{l}\text { Postpartum 2. ay BKi } \\
\left(\mathrm{kg} / \mathrm{m}^{2}\right)\end{array}$ & $\begin{array}{c}25,4 \pm 2,9(19,2- \\
32,9)\end{array}$ & $\begin{array}{c}33,4 \pm 3,3 \\
(25,9-42,7)\end{array}$ & $0,000 *$ \\
\hline $\begin{array}{l}\text { Gestasyonel ağırlık } \\
\text { kazanımı (kg) }\end{array}$ & $\begin{array}{c}16,2 \pm 5,6(5,0- \\
28,0)\end{array}$ & $\begin{array}{c}11,3 \pm 6,3 \\
(-6,0-20,0)\end{array}$ & $0,020^{*}$ \\
\hline \multicolumn{4}{|l|}{ Bebekler } \\
\hline Doğum ağırlığı (g) & $\begin{array}{c}3310,8 \pm 354,3 \\
(2640,0- \\
4140,0)\end{array}$ & $\begin{array}{c}3323,0 \pm 337,4 \\
(2800,0- \\
3860,0)\end{array}$ & 0,850 \\
\hline Doğum boyu $(\mathrm{cm})$ & $\begin{array}{c}49,9 \pm 1,5(46,0- \\
52,0) \\
\end{array}$ & $\begin{array}{c}50,7 \pm 1,6 \\
(48,0-54,0) \\
\end{array}$ & 0,215 \\
\hline 2. ay ağırlığı (g) & $\begin{array}{c}5449,0 \pm 787,4 \\
(4000,0- \\
6900,0) \\
\end{array}$ & $\begin{array}{c}5754,5 \pm 671,0 \\
(4670,0- \\
7000,0) \\
\end{array}$ & 0,285 \\
\hline 2. ay boyu $(\mathrm{cm})$ & $\begin{array}{c}57,8 \pm 3,3(51,0- \\
62,5) \\
\end{array}$ & $\begin{array}{c}58,2 \pm 2,3 \\
(54,0-62,0) \\
\end{array}$ & 0,838 \\
\hline $\begin{array}{l}\text { 2. ay boya göre ağırlık } \\
\text { z skoru }\end{array}$ & $\begin{array}{c}0,25 \pm 1,01 \\
(-1,32-2,29)\end{array}$ & $\begin{array}{c}0,64 \pm 1,20 \\
(-1,21-3,44) \\
\end{array}$ & 0,279 \\
\hline
\end{tabular}

Normal vücut ağırlığına sahip annelerin yaş ortalaması 27,1 yıl ve obez annelerin yaş ortalaması 29,5 yıl bulunmuştur. Gestasyonel ağırlık kazanımı normal vücut ağırlığına sahip annelerde obez annelere göre daha yüksek olduğu gösterilmiştir $(p=0,020)$. Bebeklerin vücut ağırlıkları, boy uzunlukları gibi antropometrik ölçümleri ve boya göre ağırlık $z$ skor değerleri arasında gruplar arasında anlamlı fark tespit edilmemiştir.

Anne sütündeki leptin, ghrelin, adiponektin ve IGF-1 konsantrasyonlarında normal vücut ağırlığına sahip anneler ile obez anneler arasında anlamlı bir fark bulunmamıştır (Tablo 2).

Tablo 2: BKl'ye göre anne sütü hormon konsantrasyonlarının karşılaştırılması

\begin{tabular}{|l|c|c|c|}
\hline Hormonlar & $\begin{array}{c}\text { Normal } \\
\text { Ortanca (Alt-Üst) }\end{array}$ & $\begin{array}{c}\text { Obez } \\
\text { Ortanca (Alt-Üst) }\end{array}$ & $\mathbf{p}$ \\
\hline Leptin $(\mathrm{ng} / \mathrm{mL})$ & $0,07(0,01-0,31)$ & $0,07(0,01-0,22)$ & 0,634 \\
\hline Ghrelin $(\mathrm{pg} / \mathrm{mL})$ & $170,59(7,35-301,91)$ & $174,65(50,88-350,01)$ & 0,907 \\
\hline Adiponektin $(\mathrm{ng} / \mathrm{mL})$ & $12,82(9,91-13,70)$ & $12,63(6,82-13,31)$ & 0,083 \\
\hline IGF-1 $(\mathrm{ng} / \mathrm{mL})$ & $0,22(0,16-0,40)$ & $0,25(0,12-0,45)$ & 0,379 \\
\hline
\end{tabular}

Anne sütündeki hormonlar ile bebeğin ağırlık kazanımı, boya göre ağırlık z skoru ve maternal BKi'nin korelasyonu Tablo 3'te verilmiştir.
Tablo 3: Anne sütündeki hormonlar ile bebeğin ağırlık kazanımI, boya göre ağırlık z skoru ve maternal BKl'nin korelasyonu

\begin{tabular}{|c|c|c|c|}
\hline & \multicolumn{3}{|c|}{ Hormonlar } \\
\hline & \multicolumn{3}{|l|}{ Leptin } \\
\hline & & $\mathbf{r}$ & $\mathbf{p}$ \\
\hline \multirow[t]{2}{*}{ Gebelik öncesi maternal BKi } & Normal & 0,829 & $0,021 *$ \\
\hline & Toplam & 0,303 & 0,254 \\
\hline \multirow[t]{2}{*}{ Postpartum 2. ay maternal BKi } & Normal & 0,857 & $0,014 *$ \\
\hline & Obez & $-0,467$ & 0,205 \\
\hline Bebeğin ağırlık kazanımı & Normal & $-0,536$ & 0,215 \\
\hline \multirow[t]{3}{*}{ Boya göre ağırlık z skoru } & Normal & $-0,857$ & $0,014 *$ \\
\hline & Toplam & $-0,318$ & 0,231 \\
\hline & \multicolumn{3}{|l|}{ Ghrelin } \\
\hline Postpartum 2. ay maternal BKi & Obez & 0,415 & 0,069 \\
\hline \multirow[t]{3}{*}{ Bebeğin ağırlık kazanımı } & Normal & 0,347 & 0,158 \\
\hline & Obez & 0,441 & 0,052 \\
\hline & Toplam & 0,406 & 0,011* \\
\hline \multirow[t]{2}{*}{ Boya göre ağırlık z skoru } & Obez & 0,446 & $0,049 *$ \\
\hline & \multicolumn{3}{|c|}{ Adiponektin } \\
\hline \multirow[t]{2}{*}{ Bebeğin ağırlık kazanımı } & Obez & $-0,428$ & 0,060 \\
\hline & Toplam & $-0,336$ & $0,034^{*}$ \\
\hline \multirow[t]{2}{*}{ Boya göre ağırlık z skoru } & Obez & $-0,325$ & 0,162 \\
\hline & \multicolumn{3}{|l|}{ IGF-1 } \\
\hline Boya göre ağırlık z skoru & Obez & $-0,343$ & 0,139 \\
\hline
\end{tabular}

${ }^{*} p<0,05$

Normal vücut ağırlığına sahip annelerin anne sütündeki leptin hormonu ile gebelik öncesi maternal BKI ve postpartum 2. ay maternal BKI arasında pozitif bir korelasyon gösterilmiştir (sırasıyla $r=0,829 ; p=0,021$ ve $r=0,857 ; p=0,014$ ). Çalışmaya katılan tüm bebeklerin ağırlık kazanımı ile anne sütündeki ghrelin hormonu arasında pozitif bir ilişki bulunmuştur $(r=0,406$; $p=0,011)$. Bebeklerin 2. aydaki boya göre ağılık $z$ skoru değerleri ile normal vücut ağırlığına sahip annelerin anne sütündeki leptin ile negatif $(r=-0,857 ; p=0,014)$, obez annelerin anne sütündeki ghrelin ile pozitif ilişki tespit edilmiştir $(r=0,446$; $p=0,049$ ).

\section{TARTIŞMA}

Maternal BKI ve maternal yaş gibi maternal özellikler anne sütündeki hormon düzeylerini etkileyebilir (15). Bu çalışmada, maternal BKI'ye göre anne sütündeki iştah hormonları miktarı karşılaştıııldığında anlamlı bir fark bulunmamıştır, ancak anne sütündeki iştah hormonları ile bebeğin büyümesi ve maternal BKI arasında anlamlı korelasyonlar bulunmuştur. Anne sütündeki ghrelin ile bebeklerin ağırlık kazanımı ve boya göre ağırlık z skoru değerleri arasında pozitif korelasyon görülmüştür. Buna ek olarak, anne sütündeki leptin hormonu ile maternal BKI arasında pozitif güçlü bir korelasyon bulunmuştur.

Maternal BKI ile anne sütündeki hormonların korelasyonu incelendiğinde, gebelik öncesi maternal BKI ve postpartum ikinci 
aydaki maternal BKI ile anne sütündeki leptin konsantrasyonları arasında pozitif bir korelasyon bulunmuştur. Bulgularımız ile benzer şekilde, 430 anne üzerinde yapılan araştırmada maternal BKI ile leptin arasında pozitif bir korelasyon bulunurken $(r=0,71 ; p<0,0001)$; maternal BKI ile adiponektin arasında anlamlı bir ilişki bulunamamıştır (16). Anne sütündeki iştah hormonları ile maternal vücut kompozisyonu arasındaki ilişkinin incelendiği bir çalışmada, yüksek maternal yağ kütlesi yüzdesinin yüksek leptin konsantrasyonu ile ilişkili olduğu bulunurken, adiponektin ile ilişkili bulunmamıştır (1). Normal vücut ağırlığına sahip 88 anne ve aşırı kilolu / obez 86 anne üzerinde yapılan bir çalışmada obez annelerin anne sütünde daha yüksek leptin seviyesi tespit edilmiştir (17). Yapılan başka bir çalışmada da benzer şekilde aşırı kilolu / obez annelerde daha yüksek leptin seviyesi gözlemlenirken, adiponektin ve ghrelin seviyelerinde anlamlı bir fark bulunamamıştır (18).

Ghrelin vücut ağırlığının düzenlenmesinde rol oynayan oreksijenik bir hormondur (19). Bu çalışmada anne sütündeki ghrelin ile bebeğin ağırlık kazanımı arasında pozitif bir korelasyon bulunmuştur. Emziren 25 anne üzerinde yapılan bir çalışmada da postpartum dördüncü ayda anne sütündeki ghrelin düzeyi ile bebeklerin ağırlık kazanımı arasında pozitif yönde anlamlı bir ilişki gösterilmiştir $(r=0,512 ; p<0,01)$. Bu kapsamda, anne sütündeki ghrelinin bebeklerin doğum sonrası yaşamın erken dönemindeki büyümesiyle de ilişkili olduğu düşünülmüştür (20). Ayrıca, yaptığımız çalışmanın sonucunda obez annelerin anne sütündeki ghrelin ile bebeklerin boya göre ağırlık z skoru arasında pozitif bir korelasyon gösterilmiştir. Anne sütü hormonları ile bebeğin büyümesi arasındaki ilişkinin araştıııdığı 67 anne bebek çiftinin dahil edildiği araştırmada anne sütündeki ghrelin ile bebeğin z skoru arasında da pozitif bir korelasyon olduğu belirtilmiştir (21). Yapılan başka bir çalışmada anne sütündeki ghrelin, boya göre ağırlık persentili normal olan bebeklerde obez olanlara göre daha yüksek bulunmuş ve ghrelinin bebeklerin vücut ağırlığı üzerinde düzenleyici etkisi olduğu savunulmuştur (22).

Bu çalışma sonucunda anne sütündeki adiponektin ile bebeğin ağırık kazanımı arasında negatif korelasyon gösterilmiş ancak anne sütündeki adiponektin ile bebeğin z skoru arasında bir ilişki bulunamamıştır. Yapılan bir çalışmada da anne sütündeki adiponektin ile bebeğin birinci, ikinci ve üçüncü ayındaki vücut ağırlığı ile negatif anlamlı bir korelasyon bulunmuştur (15). Anne sütündeki adiponektin ile bebeğin büyümesi arasındaki ilişkiyi inceleyen, en az 12 ay takip süresi olan ve 192 anne bebek çiftinin incelendiği bir araştırmada, anne sütündeki adi- ponektin ile boya göre ağırlık z skoru değeri arasında negatif ilişki gösterilmiştir (23). Anne sütündeki adiponektin ile yapılan başka bir çalışmada da ilk 6 ayda daha yüksek anne sütü adiponektini daha düşük boya göre ağırlık z skoru ile ilişkili bulunmuştur. Buna göre anne sütündeki adiponektinin bebeklerin büyümesi ve gelişmesinde rol oynayabileceği söylenmiştir (24). Normal vücut ağırlığına sahip annelerin anne sütündeki leptin ile bebeğin z skoru değeri arasında negatif bir korelasyon bulunmuştur. Yapılan bir çalışmada, daha yüksek anne sütü leptini, postpartum dördüncü ay ve birinci yaşta daha düşük boya göre ağırlık $z$ skoru ile ilişkili olduğu belirtilmiştir. Ayrıca anne sütündeki adiponektin ile bebeğin vücut kompozisyonu arasında anlamlı bir ilişki olmadığı gösterilmiştir. Anne sütü leptin hormonu ile bebeğin z skoru değeri arasındaki negatif ilişki hem istatistiksel hem de klinik olarak anlamlı bulunmuştur. (16). Başka bir çalışmada ise, anne sütündeki leptin ve adiponektin hormonu ile bebeğin büyümesi arasında bir ilişki görülmezken, anne sütündeki yüksek IGF-1 düzeyinin bebeğin 13. aydaki yüksek vücut ağırlığı ve 3 . ve 5 . yaştaki düşük vücut ağırlığı ile ilişkili olduğu görülmüştür (25). Anne sütündeki hormonların araştııılığı 103 anne bebek çiftinin katıldığı araştımada anne sütündeki IGF-1 düzeyi ile bebeğin ağırlık artışı arasında pozitif korelasyon gözlenmiştir (12). Bu çalışmada ise anne sütündeki IGF-1 düzeyi ile bebeğin ağırlık artışı veya bebeğin z skoru değerleri arasında anlamlı bir ilişki bulunamamıştır.

Sonuç olarak, maternal BKI anne sütündeki hormon düzeylerini etkileyebilir ve anne sütündeki leptin, adiponektin ve ghrelin düzeyleri bebeğin erken dönemdeki büyümesini etkileyebilmektedir. Bu hormonların bebeklerin büyümesine olan etkisini anlayabilmek için daha çok çalışmaya gereksinim vardır.

\section{KAYNAKLAR}

1. Kugananthan S, Gridneva Z, Lai CT, Hepworth AR, Mark PJ, Kakulas F, et al. Associations between Maternal Body Composition and Appetite Hormones and Macronutrients in Human Milk. Nutrients. 2017;9(3).

2. Breastfeeding. World Health Organization (WHO). Erişim tarihi: 17 Şubat 2021. Available from: https://www.who.int/ health-topics/breastfeeding\#tab=tab_2.

3. Ballard O, Morrow AL. Human milk composition: nutrients and bioactive factors. Pediatric clinics of North America. 2013;60(1):49-74.

4. Lawrence R. Breastfeeding. A guide for the medical profession. 6th ed. Philadelphia: Elsevier Mosby. 2005. 
5. Samur, G. Anne Sütü. Ankara: Sağlık Bakanlığı; 2008. Yayın No: 726.

6. Panagos PG, Vishwanathan R, Penfield-Cyr A, Matthan NR, Shivappa N, Wirth MD, et al. Breastmilk from obese mothers has pro-inflammatory properties and decreased neuroprotective factors. Journal of perinatology : official journal of the California Perinatal Association. 2016;36(4):284-90.

7. Aktaç Ş. Anne Sütü Hormonları ve Obezite Illişkisi. Turkiye Klinikleri Journal of Nutrition and Dietetics-Special Topics. 2017;3(2):80-7.

8. Savino F, Liguori SA, Petrucci E, Lupica MM, Fissore MF, Oggero R, et al. Evaluation of leptin in breast milk, lactating mothers and their infants. European journal of clinical nutrition. 2010;64(9):972-7.

9. Aydin S, Aydin S, Ozkan Y, Kumru S. Ghrelin is present in human colostrum, transitional and mature milk. Peptides. 2006;27(4):878-82.

10. Martin LJ, Woo JG, Geraghty SR, Altaye M, Davidson BS, Banach W, et al. Adiponectin is present in human milk and is associated with maternal factors. The American journal of clinical nutrition. 2006;83(5):1106-11.

11. Lind MV, Larnkjær A, Mølgaard C, Michaelsen KF. Breastfeeding, Breast Milk Composition, and Growth Outcomes. Nestle Nutrition Institute workshop series. 2018;89:63-77.

12. Kon IY, Shilina NM, Gmoshinskaya MV, Ivanushkina TA. The study of breast milk IGF-1, leptin, ghrelin and adiponectin levels as possible reasons of high weight gain in breast-fed infants. Annals of nutrition \& metabolism. 2014;65(4):317-23.

13. Body mass index-BMI. World Health Organization (WHO). Erişim tarihi: 18 Şubat 2021. Available from: https:/l www.euro.who.int/en/health-topics/disease-prevention/nutrition/a-healthy-lifestyle/body-mass-index-bmi.

14. WHO Child Growth Standards based on length/height, weight and age. Acta paediatrica (Oslo, Norway : 1992) Supplement. 2006;450:76-85.

15. Kocaadam B, Koksal E, Ozcan KE, Turkyilmaz C. Do the adiponectin and leptin levels in preterm and term breast milk samples relate to infants' short-term growth? Journal of developmental origins of health and disease. 2019;10(2):253-8.

16. Chan D, Goruk S, Becker AB, Subbarao P, Mandhane PJ, Turvey SE, et al. Adiponectin, leptin and insulin in breast milk: associations with maternal characteristics and infant body composition in the first year of life. International journal of obesity (2005). 2018;42(1):36-43.
17. Sims CR, Lipsmeyer ME, Turner DE, Andres A. Human milk composition differs by maternal BMI in the first 9 months postpartum. The American journal of clinical nutrition. 2020;112(3):548-57.

18. Young BE, Patinkin Z, Palmer C, de la Houssaye B, Barbour LA, Hernandez T, et al. Human milk insulin is related to maternal plasma insulin and BMI: but other components of human milk do not differ by BMI. European journal of clinical nutrition. 2017;71(9):1094-100.

19. Klok MD, Jakobsdottir S, Drent ML. The role of leptin and ghrelin in the regulation of food intake and body weight in humans: a review. Obesity reviews : an official journal of the International Association for the Study of Obesity. 2007;8(1):2134.

20. Cesur G, Ozguner F, Yilmaz N, Dundar B. The relationship between ghrelin and adiponectin levels in breast milk and infant serum and growth of infants during early postnatal life. The journal of physiological sciences : JPS. 2012;62(3):185-90.

21. Huang LL, Yang F, Xiong F. [Association of leptin, adiponectin, and ghrelin in breast milk with the growth of infants with exclusive breastfeeding]. Zhongguo dang dai er ke za zhi $=$ Chinese journal of contemporary pediatrics. 2018;20(2):91-6. 22. Khodabakhshi A, Ghayour-Mobarhan M, Rooki H, Vakili R, Hashemy SI, Mirhafez SR, et al. Comparative measurement of ghrelin, leptin, adiponectin, EGF and IGF-1 in breast milk of mothers with overweight/obese and normal-weight infants. European journal of clinical nutrition. 2015;69(5):614-8.

23. Woo JG, Guerrero ML, Guo F, Martin LJ, Davidson $B S$, Ortega $H$, et al. Human milk adiponectin affects infant weight trajectory during the second year of life. Journal of pediatric gastroenterology and nutrition. 2012;54(4):532-9.

24. Woo JG, Guerrero ML, Altaye M, Ruiz-Palacios GM, Martin LJ, Dubert-Ferrandon A, et al. Human milk adiponectin is associated with infant growth in two independent cohorts. Breastfeeding medicine : the official journal of the Academy of Breastfeeding Medicine. 2009;4(2):101-9.

25. Galante L, Pundir S, Lagström H, Rautava S, Reynolds CM, Milan AM, et al. Growth Factor Concentrations in Human Milk Are Associated With Infant Weight and BMI From Birth to 5 Years. Frontiers in nutrition. 2020;7:110. 